\title{
The diffusion process of stationary fuel cells in a two-sided market economy
}

\author{
Boris Heinz*, Max Graeber, A. J. Praktiknjo \\ Department of Energy Systems, Berlin University of Technology, \\ Einsteinufer 25 (TA8), 10587 Berlin, Germany \\ *Corresponding author, Tel: +49-(0)30-314-21 710, Fax: +49-(0)30-314-78 728, \\ Email: boris.heinz@tu-berlin.de
}

(C) 2013. This manuscript version is made available under the CC-BY-NC-ND 4.0 license

http://creativecommons.org/licenses/by-nc-nd/4.0/

Please cite this article as: Heinz, B., Graeber, M., Praktiknjo, A. (2013): The diffusion process of stationary fuel
cells in a two-sided market economy. In: Energy Policy, 61: 1556-1567.
http://dx.doi.org/10.1016/j.enpol.2013.06.095

\begin{abstract}
This paper presents an innovative approach to promote the hydrogen economy based on the two-sided markets theory. In the hydrogen economy, the hydrogen is delivered to the customers and is then converted into electricity and heat by fuel cells. This environmentally friendly decentralized power network consists of fuel cell manufacturers, hydrogen producers, and the purchasers of fuel cells and hydrogen.

We present the specific characteristics of networks - two-sided market effects - and describe their effectiveness of establishing a network. Because the coordination of these effects additionally helps to implement the hydrogen economy locally, we consider an intermediary in the network. To fulfil this task, we model a Bass diffusion process of fuel cells and hydrogen producers. The simulations indicate that including and coordinating the network effects can accelerate the diffusion of fuel cells and hydrogen supply significantly-fuel cell installations can be doubled in the first 5 years.
\end{abstract}

Keywords: $\quad$ hydrogen economy, two-sided markets, network effects

\section{Introduction}

We know about the fuel cell technology and its advantages since the 19th century, but we do not yet benefit from the economic and environmental advantages of an extended hydrogen economy. Among other applications, fuel cells are used in transportation and for decentralized power supply, but they are still away from their market potential. The underlying approach of this paper is a turning away from the traditional perception on how fuel cells shall be introduced. We do not believe that starting with the installation of fuel cells will lead to a hydrogen supply and establish the hydrogen network. A different approach is needed. We suggest coordinating the two-sided market effects that are predominant by an intermediary in order to accelerate the emergence of the hydrogen market. 
There are many arguments in favor of using fuel cells. Reducing the total fuel cell size of an installation does not induce efficiency losses, so they are also applicable for decentralized power generation, e.g. two small, local fuel cell systems are just as efficient as one larger central fuel cell system. Fuel cells have a constant relative efficiency, which means that a decrease in the degree of capacity utilization, e.g. down to $80 \%$, does not reduce the degree of efficiency much compared with a total capacity utilization. In other words, fuel cells are able to operate efficiently, independent of changes in the energy demand. This technology is economically applicable to small-scale installations and can be installed in single-family houses and used for combined heat and power generation. Due to the generation close to the consumer transportation losses are not existent and the heat produced during electricity generation can be used easily. With largescale power plants such as condensation power stations the utilization of the by-product heat is mostly not possible. In addition to that fuel cells operate without noise and without visible vapor or gaseous emissions. For these reasons they enhance the convenience of power generation and should meet with broad social acceptance.

Following the comparison between centralized power systems and decentralized power systems, economic advantages can be found in favor for the decentralized power generation with fuel cells. In contrast to centralized power systems that are produced in relatively low numbers, fuel cells can and hopefully will be produced in high numbers. By producing more units of smaller power systems, a mass market with lower unit costs can emerge. The economies of scale and the higher efficiency, as mentioned before, show that decentralized fuel cell systems may also compete with centralized combined cycle power plants. In centralized energy systems there is also a need to build transport capacities in order to get the electricity to the centers of consumption. Building power grids is a very costly investment and, in the end, consumers will have to bear the costs. Additionally, big power grids also induce distribution losses. Because fuel cells can be located close to power users there are almost no distribution losses. Finally, the security of supply is increased, too. A breakdown of one fuel cell in a system will have little effect as the capacity of one unit compared to the whole installed capacity is low. The impact of a power cut in a centralized power system would be much greater.

Fuel cells powered by hydrogen generate electricity and local heat without emitting any greenhouse gases. So, combined with fuel cells, hydrogen provides the greatest utility: environmentally friendly energy supply. There are several ways to produce hydrogen. Today, the most common way is by conversion of natural gas on site. But this releases greenhouse gases e.g. carbon dioxide. An environmentally friendly hydrogen production would be the electrolysis with wind power as considered and currently tested with a hybrid power plant from Enertrag AG (www.enertrag.com) in Germany. In some areas the supply of electricity generated by wind power plants exceeds the local demand, e.g. in northern Germany. In such a case the excess wind power generation can be used for hydrogen production through electrolysis.

For doubters of the hydrogen network there is a fallback option. Fuel cell operation is also possible with bio-gas. As the bio-gas is often produced in rural areas and expensive gas pipelines have to be built to transport the gas to the customers it is also possible to locate fuel cells close-by and establish a bio-gas fuel cell network.

Many products have little value in isolation but generate great value when combined with others (Katz and Shapiro, 1994). Fuel cells and the hydrogen production only deliver the greatest value together and therefore form a network. But networks may also feature challenges as they imply externalities. ${ }^{1}$ These are positive or negative dependencies of demand (Katz and Shapiro, 1985, 1994). This means that the demand for hydrogen depends on the numbers of fuel cells sold and the sales volume of fuel cells depends on the availability of hydrogen. These effects have to be internalized in order to establish a hydrogen network.

Please cite this article as: Heinz, B., Graeber, M., Praktiknjo, A. (2013): The diffusion process of stationary fuel cells in a two-sided market economy. In: Energy Policy, 61: 1556-1567.

http://dx.doi.org/10.1016/j.enpol.2013.06.095 
Fuel cells are used in many application areas. In this paper we are focusing on the innovative technology of fuel cells for residential heat and power generation and combine it with the novel marketing network approach of "two-sided markets". We first outline the technology of fuel cells and hydrogen production and then we describe the interrelations between the fuel cells, the hydrogen producers and the consumers of both goods and the network effects. Focusing on network effects, we do not take account of economic concerns, which would strongly influence the rate of adoption in reality as well. We also describe the matching function of a worthwhile intermediary. Finally, we estimate the accuracy of the theoretical findings by modelling a diffusion process of the fuel cells and the hydrogen production facilities.

The results are backed up by a sensitivity analysis. We also provide an inter-annual distribution analysis of the model's outcome. Visualizing the outcomes by area diagrams supports the appropriateness of the average values of the diffusion model's parameters we use. The outcome is a feasible marketing strategy for a local hydrogen economy. This approach helps to overcome the difficulties of initiating a network and in this manner facilitating decentralized power production which is important for sustainable power generation with very low greenhouse gas emissions.

\section{Technological fundamentals}

In order to understand the characteristics of the hydrogen economy one has to understand the underlying technologies. Therefore, this section presents an overview of the fuel cell technology and the electrolysis as a reasonable hydrogen production option.

\subsection{Fuel cells}

Fuel cells are electrochemical converters that use hydrogen and air in order to generate heat and electricity. Fuel cells are able to reach higher efficiencies than it is possible with conventional combustion power plants. In most of the conventional power plants heat (thermal energy) is generated and then used in a turbine to generate electricity. Fuel cells convert chemical energy directly into electrical energy.

For stationary applications there are two main types of fuel cells that are interesting. One option is to use a high-temperature fuel cell like Solid Oxide Fuel Cell (SOFC) or Molten Carbonate Fuel Cell (MCFC) and the other possibility is to use a low temperature fuel cell like the Proton Exchange Membrane Fuel Cell (PEMFC). The higher operating temperatures of the SOFC and MCFC results in stop, start and dynamic characteristics that are not ideal for small-scale residential applications. For this reason and because PEMFCs are more advanced, this paper assumes their installation. The basic principle of a PEMFC is shown in Fig. 1. The grey plates on the left and right hand side of the Proton Exchange Membrane (PEM) are the anode and cathode. At the negative loaded anode side the hydrogen is split catalytically into protons and electrons. The PEM is only permeable for positively charged particles. So the protons pass through whereas the electrons follow the way up around the PEM in order to build the electric circuit. They do so because they are energised by the positive loaded cathode. At the 


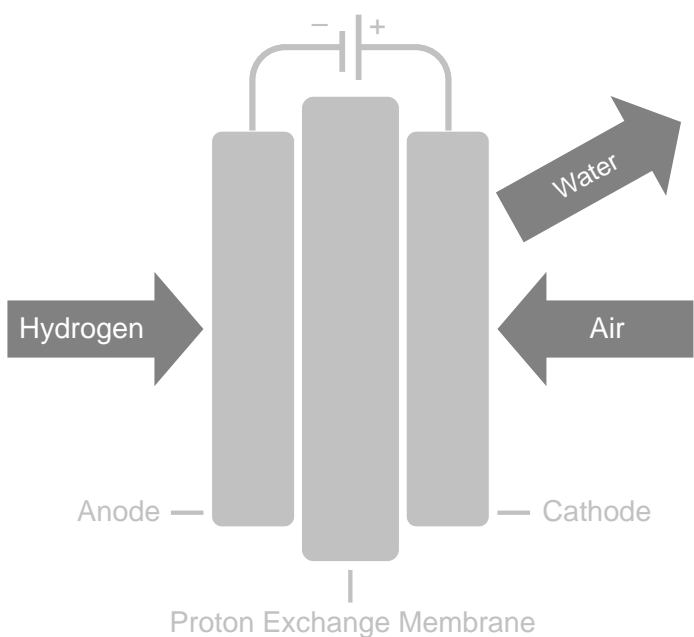

Figure 1: Scheme of the fuel cell process



Figure 2: Scheme of the electrolyzer process

cathode, water is formed catalytically from protons, electrons and oxygen from the air stream. The overall reaction in the fuel cell is exothermic and produces heat as a 'waste product'. Through their high efficiency as combined heat and power plants and the possibility of using non-fossil fuels, fuel cells contribute to the protection of the resources and to the reduction of greenhouse gases.

\subsection{Hydrogen production and electrolyzers}

Electrolysis is the process to generate the hydrogen from water with the aid of electricity. It is the reverse process to the underlying process in a fuel cell. Again, a PEM separates the protons from the electrons (see Fig. 2). At the anode, water is split into protons, electrons and oxygen. The oxygen is removed. The protons diffuse through the PEM towards the cathode where they form hydrogen. The power supply unit indicated at the top of Fig. 2 stands for the wind power plant that feeds in.

Another possibility to generate the hydrogen can be the reformation of natural gas or the gasification of biomass. Therefore e.g. natural gas is mixed with steam and heated. Reactions take place and form carbon monoxide, hydrogen and further hydrocarbons. After a separation process hydrogen is obtained.

Hydrogen with highest purity is yielded directly by electrolysis. Electrolysis with electricity from renewable sources is also the most mentioned source for future hydrogen production in the European HyWays ${ }^{2}$ project. As it is also the most suitable solution for the hydrogen economy considered in this paper, the paper focuses on electrolysis with wind electricity in the following.

There are some technical and legal restrictions on wind farm sites and the location of hydrogen production plants. They have to be located close to each other as the construction of pipelines to supply the fuel cells continuously is very costly and supply network length has to be minimized. But profitable hydrogen production plants need customers in their surroundings. For this reason, the hydrogen customer - fuel cell owner - has to be sited near the plants. Thus, information and coordination problems arise. A further economic advantage of locating hydrogen customer close to the production sites are the economies of scale. Within a European Commission project at the "Universidad de Las Palmas de Gran Canaria" such a wind-hydrogenfuel-cell system is going to be built up on the Canary Islands. In that special case the three main 
islands meet all of the above-mentioned conditions. Wind power will be converted into electricity that is then converted in an electrolyzer into hydrogen and then used by fuel cells in order to generate heat and electricity. On these islands the supply network can be established easily. No matter where the production sites are located the distances to the customers never exceed $45 \mathrm{~km}$.

\section{Economic fundamentals}

This section aims to show that fuel cells, hydrogen and their producers as well as the customers of both goods form a network - the hydrogen network. An overview is given of networks and especially the specific characteristics of networks - the network effects and the matching function. Networks are increasingly interpreted with the two-sided markets approach (Armstrong, 2006; Caillaud and Jullien, 2003; Eisenmann et al., 2006; Parker and Van Alstyne, 2005; Rochet and Tirole, 2003; Sun and Tse, 2007). Therefore, we also use this theoretical framework in order to discuss the hydrogen economy.

\subsection{Characteristics of networks}

Most networks imply network externalities. An externality is an uncompensated effect of economic decisions for uninvolved market participants (Katz and Shapiro, 1985). More specific network externalities are positive or negative dependencies of demand (Katz and Shapiro, 1985, 1994). In this context, the market has supply and demand sides. The supply side is searching for customers and the demand side is asking for suppliers and their products. Positive network externalities raise the utility for certain market participants depending on the other market participants. Negative network externalities lower the value for the affected people. Therefore, if network externalities exist, one market side's decisions are based on the expected decisions of the other market side.

Besides the network effects, the matching necessity is a further important character of networks (Bakos, 1997). In networks at least two market sides have to be pooled. One market side consists of the producers and sellers of goods and the other side includes potential customers. Due to network effects, the coordination of supply and demand is challenging because there are often no linear dependencies but rather self-energizing loops.

\subsubsection{Network externalities}

The most famous characteristics of networks in scientific literature are externalities. Katz and Shapiro (1985) introduced this positive dependence of demand. They were the first to assume that consumers base their purchase decisions for network goods not only on the goods themselves but also on their expectations about the future market size. Due to the characteristics of these goods - network effects - the consumers also profit by other customers' transactions. In networks, the utility that a user derives from a given network good also depends on the amount of the other users' transactions. This is the so-called direct effect. The most famous example is the telephone network. In this case, the utility of the product depends directly on the number of others using the same product (Katz and Shapiro, 1985).

In case of indirect dependence, the utility of a certain good depends on the number of other complementary products and the customers of those products (Stremersch et al., 2007). In such a setting, the main network good is often named 'hardware' whereas the complementary

Please cite this article as: Heinz, B., Graeber, M., Praktiknjo, A. (2013): The diffusion process of stationary fuel cells in a two-sided market economy. In: Energy Policy, 61: 1556-1567.

http://dx.doi.org/10.1016/j.enpol.2013.06.095 
products are labelled 'software'. An indirect effect exists if the demand for the 'hardware' is affected by the increased supply of complementary products, the 'software', or vice versa (Gupta et al., 1999).

In our present hydrogen economy, a customer has to buy two components, the fuel cell and the hydrogen, in order to obtain the highest benefit. Thus, the consumers' utility depends on both goods and for this reason there are indirect network effects. An implicit condition of network effects is that the customers make their purchases over time-either because consumers enter the market at different times or because a given consumer may spread purchases over time as preferences change (Katz and Shapiro, 1994). For example, the choice of a fuel cell in the first period means a customer is locked in. After that, he has to anticipate what will happen in the second period, if the hydrogen will or will not be available. As a result, demand in the first period will depend on his expectations about the second period. So, in these marketplaces externalities come about indirectly, through the impact of one consumer's adoption decision on the future variance or prices of components.

\subsubsection{Two-sided markets and their inherent effects}

Networks often are shaped by two-sidedness. That means that there are at least two market participants. Fig. 3 illustrates a market's two-sidedness by means of the hydrogen-network. Fuel cell manufacturers and hydrogen producers represent one side of the market and consumers represent the other.

The two-sided market approach derives from the payment card market, which is a typical twosided market where two groups of agents interact, e.g. merchants and cardholders. The value for one group of this network depends on the number of the other group. For example, a high number of consumers holding a credit card will allow the merchants to generate high sales volumes with this credit card. On the other hand, the high sales potential with the credit card results in a high number of merchants accepting this credit card. This high number of accepting stores facilitates the payment for credit card holders and attracts more credit card holders. Markets with such cross-side network effects (cross-side effects) ${ }^{3}$ are termed as "two-sided markets" (Armstrong, 2006; Rochet and Tirole, 2003; Sun and Tse, 2007). So not the two- sidedness itself but the two-sided market effects are the specific characteristic. Fig. 3 outlines the interconnections between both market sides, namely the cross-side effects, by blue connecting lines. Additionally, same-side effects ${ }^{4}$ appear, illustrated by orange lines.

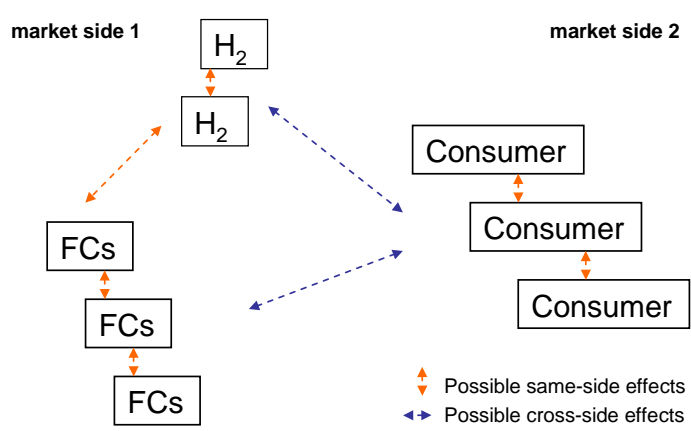

Figure 3: fuel cell - hydrogen network

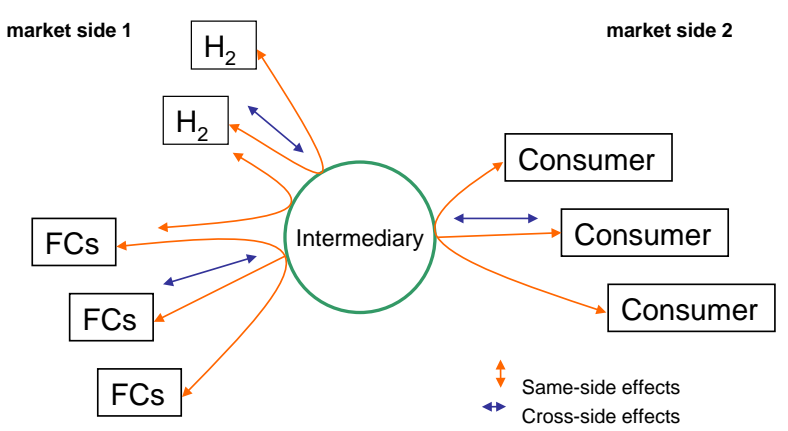

Figure 4: hydrogen network with two-sided market effects

A cross-side effect exists when increasing the number of users on one side of the network makes it either more or less valuable to the users on the other side (Eisenmann et al., 2006). 
Cross-side effects are typically positive but can be negative in some cases. Examples of negative cross-side effects are TV viewers who prefer fewer ads.

The cross-side effect is a double-edge sword. It can either lead to spiral growth of the network or create the chicken-and-egg problem (Sun and Tse, 2007). As mentioned above, customers of network goods also take their expectations of the future market size into consideration when facing a purchase decision. Therefore, it is possible that the customers wait in order to adopt 'hardware' until enough 'software' is available, and 'software' manufactures delay releasing 'software' until enough customers have the 'hardware' (Stremersch et al., 2007). In our context, one has to ask which technology should come first in order to enable the market entry of the other technology. This is important because unless the network has reached a critical mass in the number of participants it cannot take off. The prerequisite of the network's ignition is the solving of the chicken-and-egg problem.

Same-side effects are present when drawing users to one side helps to attract even more users to that side. In other words, increasing the number of users on one side of the network makes it either more (or less) valuable to users on the same side (Eisenmann et al., 2006). On the business-to-business (B2B) side of a two-sided market, same-side effects are often negative because sellers prefer fewer rivals. In contrast, in the hydrogen-network the same-side effects on the B2B side are positive. The hydrogen producers benefit from an increasing number of fuel cell manufacturers because their market potential rises. The reverse also applies. Fuel cell producers benefit from a large number of hydrogen producers because ready availability of hydrogen induces higher sales of fuel cells. On the consumer side of a two-sided market the same-side effects may be positive. For example, if the number of fuel cell customers in a particular area reaches a critical level, hydrogen suppliers will enter the market. In this way, the increase in customers on the demand side enhance their utility by a more convenient hydrogen supply.

However, the two-sided market effects do not only enhance the market participants' utility but also lowers the service provisioning cost. The increase of the user's number by two-sided effects induces a higher capacity utilization. In a market with almost perfect competition, this cost advantage may imply lower prices. Thus, two-sided market effects have a double benefit for customers - by increasing their utility and reducing the service prices. As a result, these effects are both value and cost drivers. To illustrate the impact of both elements of the twosided effects again the credit card industry can be used. A high number of accepting stores of a particular credit card can drive stores which do not accept any card to decide for that particular credit card because it already has a significant number of users. The reason might be that because the operating costs of the network are born by a higher number of users the credit card service can be offered for lower fees. It also has to be stressed that the credit card has to deliver an additional benefit; otherwise this extra service becomes redundant. In the payment market credit cards lower the transaction costs.

\subsubsection{Matching - Coordination problem}

Already in 1970 George A. Akerlof demonstrated that without sufficient and sensible information a market can fail (Akerlof, 1970). He exemplifies on a car market that asymmetric information between buyers and sellers not only hinders the transactions but even leads to market collapse. To allow all participants an almost rational decision-making process, market information has to be made accessible for every market member. An intermediary like a website can now fulfill this information function. But for an efficient matching of both market sides it

Please cite this article as: Heinz, B., Graeber, M., Praktiknjo, A. (2013): The diffusion process of stationary fuel cells in a two-sided market economy. In: Energy Policy, 61: 1556-1567.

http://dx.doi.org/10.1016/j.enpol.2013.06.095 
is not only necessary to overcome the information asymmetries, it is also important to reduce the buyers' search costs. Intermediaries between buyers and sellers are able to lower the buyers' costs to acquire information about seller prices and product offerings (Bakos, 1997).

But the provision of information is not the only prerequisite for the existence of an intermediary. As mentioned above, indirect externalities arise in networks and are liable to pose chickenand- egg problems (Caillaud and Jullien, 2003; Gupta et al., 1999). This also threatens the hydrogen-network. There should be a third participant, e.g. a platform-intermediary, besides the content producers (fuel cell manufacturer and hydrogen producer) on the one market side and the end consumers on the other side of the market. Then the intermediary can link both market sides as well as direct the network effects (Eisenmann et al., 2006; Parker and Van Alstyne, 2005; Rochet and Tirole, 2003).

\subsection{Hydrogen-network as a two-sided market}

Our exemplary two-sided energy market is made up of three participant groups including the fuel cell manufacturers, hydrogen producers and customers of both goods. Between these groups there are positive feedbacks and network externalities. If more consumers buy and run fuel cells, more hydrogen producers will appear which makes this energy system more appealing to consumers and draws additional customers into the hydrogen economy.

Fig. 4 shows a fuel cell hydrogen network with an intermediary, who bundles the cross-side and same-side effects. The same-side effects occur between the market participants of each side as shown in Fig. 3. Additionally, all effects are merged by an intermediary, e.g. a website, and that way enable the connection of each participant of one side with all other participants of the same side. Because the interdependencies in this scenario do not only connect each participant with one particular but almost all participants of the same side, the impact of the sameside effect skyrockets. The cross-side effect in the hydrogen economy also emerges between both market sides as shown in Fig. 3. However, in a market with an intermediary they are boosted as the intermediary 'gathers' the network members of both sides and shows how many participants there are. In this way the market members of one side know about their potential counterpart and therefore they can market their offerings in order to achieve customers. The customers themselves can buy fuel cells, because with a sufficient market size it is quite sure that hydrogen producer will enter the market if they are not yet there.

If the interrelations of the network participants are known to and implemented by the intermediary, it is possible to visualize the two-sided market effects. So, a market member does not have to estimate the size of the market, which is an important variable for joining this specific network. Each participant has the same, complete market information. The intermediary enables an almost rational decision-making process. By disclosing the future market size, an intermediary lowers the uncertainty of market entry for all market participants.

A possible cause-and-effect relationship of the diffusion of fuel cells and hydrogen production can bear as follows. The fuel cell technology for small residential sites already exists. To accelerate their market diffusion, they should be marketed by a website. The potential customers can find out about buying and installing a fuel cell much faster. After a successful installation the customers will tell new potential customers about the technology and draw them to the website and the network. The same-side effect occurs and enhances itself, because the more potential customers will be drawn to the website the more people can tell about it and draw more potential customers. If the hydrogen producers want to join the network, they visit the website in order to check the local market of fuel cell suppliers and their purchasers. Here there

Please cite this article as: Heinz, B., Graeber, M., Praktiknjo, A. (2013): The diffusion process of stationary fuel cells in a two-sided market economy. In: Energy Policy, 61: 1556-1567.

http://dx.doi.org/10.1016/j.enpol.2013.06.095 
are same-side effects between the fuel cell and hydrogen producers, and cross-side effects between the hydrogen producers and fuel cell customers. When the network is large enough, the hydrogen producers enter the market. The potential customers know that and do not hesitate until both products are available. Furthermore, certain fuel cells are able to run on natural gas by converting it into hydrogen. Because the hydrogen producers also know about the customers' behavior, they do not delay their investment decision for a hydrogen production site in that particular local network either. In this way, the two-sided market effects can speed up the market penetration so that the critical size is reached (Birkner and Heinz, 2008).

Summing up, both people and technology drive the technology innovation.

\section{Diffusion process}

The economic literature on two-sided markets focuses on social welfare implications in static equilibrium model settings (Sun and Tse, 2007). This paper differs in two aspects: we are searching for managerial alternatives to solve the chicken-and-egg problem and are using a dynamic approach. In this scenery each individual forms an expectation of how many other side agents will have attended the network by the end of the decision-making process. For that purpose, one needs to assume that all individuals have correct and fulfilled expectations, respectively, of other agent's participation. The chicken-and-egg problem occurs when the market participants have such low expectations of other agents' participation that nobody finds it worth participating. In equilibrium all initial expectations are fulfilled so nobody anticipates new network entrants (Katz and Shapiro, 1994). But the market does not have to result in such a static equilibrium, as is shown below.

This model is made up of two players on market side 1 (business-to-business side), the fuel cell manufacturers and the hydrogen producers. Because both players are reliant on each other (fuel cells need hydrogen to work in an environmentally friendly way and hydrogen requires fuel cells to create demand) same-side effects occur within one side of the market. Because of product complementarities both competitors can cash in on positive feedback. For this reason, they are not competitors but business partners. We observe positive same-side effects. Market side 2 (end consumer side) consists of customers of fuel cells and hydrogen. The hydrogen economy also exhibits network effects across the market. These cross-side effects run from consumers to the content providers (Bakos, 1997; Katz and Shapiro, 1985). There are cross-side effects because it is more likely that hydrogen producer will start up their business when there are many fuel cell customers and existing hydrogen producers will encourage people to buy fuel cells.

Having studied the network theory focusing on two-sided market effects in a hydrogen network, a variety of validated diffusion models have been studied in order to determine to what extent they can be applied to the modelling and the qualitative visualization of the effects. Attention was focused on the ability to incorporate the same-side and cross-side effects. These requirements are met by the Bass model, a growth model for the timing of initial purchase of new products developed by Bass (1969). An important variable is the market share. The applicability of the Bass diffusion model in our context is demonstrated by Kalish and Lilien (1983) who applied it to the analysis of new energy systems' diffusion. To have an ongoing diffusion process, the critical mass has to be reached (Meade and Islam, 2006). As Barreto et al. (2003) point out, fuel cells operating on hydrogen will become a central part in heat and electricity supply in the 21st century. Due to a high efficiency and low greenhouse-gas emissions, fuel cells are more environmental friendly than oil or natural gas fueled systems.

Please cite this article as: Heinz, B., Graeber, M., Praktiknjo, A. (2013): The diffusion process of stationary fuel cells in a two-sided market economy. In: Energy Policy, 61: 1556-1567.

http://dx.doi.org/10.1016/j.enpol.2013.06.095 
Additionally, fuel cells are independent of the oil price when they are run on hydrogen from renewable energy sources. Fuel cells have high investment costs that will decrease in the future due to technical progress. Assuming the fuel cells' investment costs were equal to fossil fueled combined heat-and-power generators, fuel cells would be able to penetrate the whole market. Therefore, we use the model framework of modelling technological choice as a diffusion process (Decanio and Laitner, 1997). There also exists an approach to model technological choice as an investment which does not allow the technology to achieve complete market penetration. Thus, we chose a more realistic approach and model the customer's choice for fuel cells as a diffusion process.

\subsection{The theory}

The Bass diffusion model describes how new products are adopted as an interaction between users and potential users and is widely used in product and technology forecasting. The underlying principles of the adoption and diffusion process of new ideas or products by a social system stem from Rogers (2003). The key ideas of the theory are outlined as they apply to the timing of adoption.

The innovation-decision-implementation process through which an individual passes can be described in five stages. At first, individuals have different selective exposure to or awareness of news and they have different knowledge (1). Second, the individual's positive or negative attitude towards the innovation and their persuasion due to possible relative advantages of the innovation has an effect (2). This is followed by a decision process resulting in an adoption or a rejection of the innovation (3). Rogers introduced perceived characteristics of innovations that consist of "relative advantage", "compatibility", "complexity”, "triability” and "observability". Based on these five criteria, individuals perceive an innovation as new or useful and decide either to adopt or refuse it. Afterwards the implementation follows as a regular or standard practice (4) to come to the confirmation of the new idea by comparing and evaluating the innovation (5) (Rogers, 2003). Even though the aforementioned five steps can be assumed to be valid for all individuals in a social system, the timing of the innovation-decision-implementation process for each individual can be different in time due to their involvement in that respective innovation process.

Some individuals decide to adopt an innovation independently of the decisions of other individuals in the social system. These individuals are named innovators. Ordinarily it might be expected the first adopters to be innovators. They can be defined as the first two and one-half percent of adopters and are described as being venturesome and daring (Rogers, 2003). They interact with other innovators but are not influenced in the timing of purchase by other members of the social system. The pressure of adoption for this group of people does not increase with the growth of the adoption process. Apart from innovators, the other adopters referred to as the imitators, are influenced in the timing of adoption by the pressures of the social system. The pressure for later adopters increases with the number of previous adopters as they are influenced in the timing of adoption by the decisions of other members of the social system and learn in some sense from earlier adopters. In the literature the following classes of adopters are specified: (1) Innovators, (2) Early adopters, (3) Early majority, (4) Late majority and (5) Laggards (Bass, 1967).

Please cite this article as: Heinz, B., Graeber, M., Praktiknjo, A. (2013): The diffusion process of stationary fuel cells in a two-sided market economy. In: Energy Policy, 61: 1556-1567.

http://dx.doi.org/10.1016/j.enpol.2013.06.095 


\subsection{The model}

In the mathematical formulation of the Bass model the groups (2) to (5) are aggregated and are defined as imitators, and group (1) is defined as the innovators. For these two groups of adopters a precise and basic assumption to characterize the theory of the timing of initial purchase of a new consumer product is presented in Bass (1969). He suggests modelling an initial purchase at time $T$ given that no purchase has yet been made as a linear probability function of the number of previous buyers. This relation can be expressed as:

where:

$$
P(T)=p+\left(\frac{q}{m}\right) \times Y(T)
$$

$P(T) \quad$ Probability of purchase at time $T$

$p \quad$ Coefficient of innovation

$q \quad$ Coefficient of imitation

$m \quad$ Market potential

$q / m \quad$ Pressure operating on imitators as the number of previous buyers increases

$Y(T) \quad$ Number of previous buyers at time $T$

The coefficient of innovation $p$ stands for the external influence or the advertising effect, the probability of an initial purchase and the importance in the social system. The coefficient $q$ is the internal influence, e.g. word-of-mouth. The pressure operating on imitators is caused by the number of previous buyers and is described by the product of $q / m$ and $Y(T)$. The parameters $p, q$ and $q / m$ are constants.

At the beginning of the adoption period, $Y(T)$ is 0 as there are no previous buyers. The relation for $P(T)$ then reduces to the constant $p$ as the probability of an initial purchase at time $T=0$. Its magnitude reflects the importance of innovators in the social system. With the parameters that depend on time, it is possible to select a unit of measure for time so that $p$ reflects the fraction of all adopters who are innovators in terms of Rogers (2003). The pressure operating on imitators increases with increasing number of previous buyers. In the subsequent derivation of the model, the term for $P(T)$ is handled as a linear probability element for each point of time in order to formulate the theory in terms of a continuous model and a density function to initial purchase. For further information to the model's derivation and the solution of the difference equations that result from this problem it is referred to Bass and the Appendix (Bass, 1969).

Before showing how the model is applied to the situation in a hydrogen network, its two assumptions for the purchase of the product and the behavioral rationale are mentioned. Within the period of interest, the lifetime of the product, there will be $\mathrm{m}$ initial purchases of the product. Since it is dealt here with infrequently purchased products, the unit sales of the product will coincide with the number of initial purchases during that part of the time interval for which replacement sales are excluded. Given that no purchase has yet been made, a likelihood of purchase at time $T$ is derived and included. The model also implies that initial purchases can be made by innovators as well as by imitators. Innovators and imitators are distinguished in the model according to how they are influenced in their timing of initial purchase. Innovators are not influenced by the number of people who have already bought the product, but imitators are. In conclusion, the importance of innovators will be greater at first and will diminish with time (see also in Sections 5.4.1 and 5.4.2).

Please cite this article as: Heinz, B., Graeber, M., Praktiknjo, A. (2013): The diffusion process of stationary fuel cells in a two-sided market economy. In: Energy Policy, 61: 1556-1567.

http://dx.doi.org/10.1016/j.enpol.2013.06.095 


\subsection{Application}

An adapted version of the Bass model has been applied in order to show the accelerated diffusion of fuel cells and hydrogen production. Therefore, variations in the two coefficients have been used to reflect the differences between no side and side effects in the following three scenarios. A projection of the same-side effects through variations in the coefficient of imitation $q$ and a projection of the cross-side effects through the variation of the coefficient of innovation $p$ seemed to be justified.

Same-side effects can be represented by the imitators learning from earlier adopters and by seeing how the technology is already in use, by word-of-mouth. On the producer market side, firms perceive how many firms have already joined the network and feel in some sense a pressure also to join the network.

The cross-side effects can be seen as adjusted by the parameter $p$ as it represents the enhanced information flow through the network from firms on the one side of the market to the users on the other side of the market. Among the users considered here, mainly innovators are open to receive the information as they adopt the technology independently of the number of previous adopters. Innovators are only influenced by the information they get and their personal choice to adopt the technology. The imitators' decisions are clearly influenced by the number of previous adopters.

As will be seen later on in the sensitivity analysis, the time dependency of both coefficients and both side effects correlates. At the beginning of the process, innovators play the major role but this then decreases monotonically with time. A similarity with the cross-side effects can be found in that cross-side effects improve the diffusion mainly at the beginning by enhancing the information flow between the two sides.

During the subsequent diffusion process, imitation becomes more and more important as individuals adopt according to the number of previous adopters. The same-side effects evolve as we see on both market sides a pressure operating on the firms to join the network and a pressure operating on the consumers to imitate the adoption of the technology. Both effects also tend to increase with time.

The parameters used in the final model formulation are:

It $\quad$ Total number of installed fuel cells at time $t$

$I_{t-1} \quad$ Total number of installed fuel cells at time $t-1$

$m \quad$ Market potential

$p \quad$ Coefficient of innovation

$q \quad$ Coefficient of imitation

$q / m \quad$ Pressure operating on imitators as the number of previous buyers increases

The central equation then can be written in terms of the installed fuel cells at time $t$ :

$$
I_{t}=I_{t-1}+p \times\left(m-I_{t-1}\right)+q \times \frac{I_{t-1}}{m} \times\left(m-I_{t-1}\right)
$$

For the modelling the software package Matlab is used. The information about how the parameters have been set and the resulting order of magnitude of the improved diffusion process in contrast to the standard diffusion process are presented in the following chapter. 


\section{Results}

Three scenarios are presented for the deployment of the network strategies and the inclusion of their effects. Differences in the scenarios are made by first separating and showing the sameside and cross-side effects before incorporating both effects into the final scenario. In addition, a reference diffusion curve is given for the standard diffusion process. We provide a sensitivity analysis as well as an inter-annual distribution analysis of the outcome. The results are visualized by an area diagram.

\subsection{Standard diffusion scenario}

For the standard diffusion scenario an approximation of future developments within a hydrogen economy is performed. The aim was to analyze the forces influencing the diffusion process of fuel cells within Germany's heating market. For this purpose, the real diffusion of all major heating technologies in the German residential heating market over the past 20 years is studied. Using yearly sales numbers of the respective system and a regression realized with the TrustRegions-Algorithm values for the parameters of innovation, imitation and for the market potential are determined. Table 1 shows the resulting parameters for the respective technology. To obtain diffusion parameters similar to the future market development of fuel cells in Germany's heating appliances market the different technologies have to be analyzed regarding its suitability for comparison. The most basic assumption is that all technologies examined serve the same market and are hence comparable in their market development. This might be questionable at second glance, for technologies using combined heat-and- power, such as the fuel cell. If taking into account though, that a heat-and-power generator can only be run efficiently when operated to meet the heating demand and then the electricity demand, the initial assumption is justified. All technologies presented are potential competitors. 
Table 1: Overview diffusion characteristics of comparison technologies

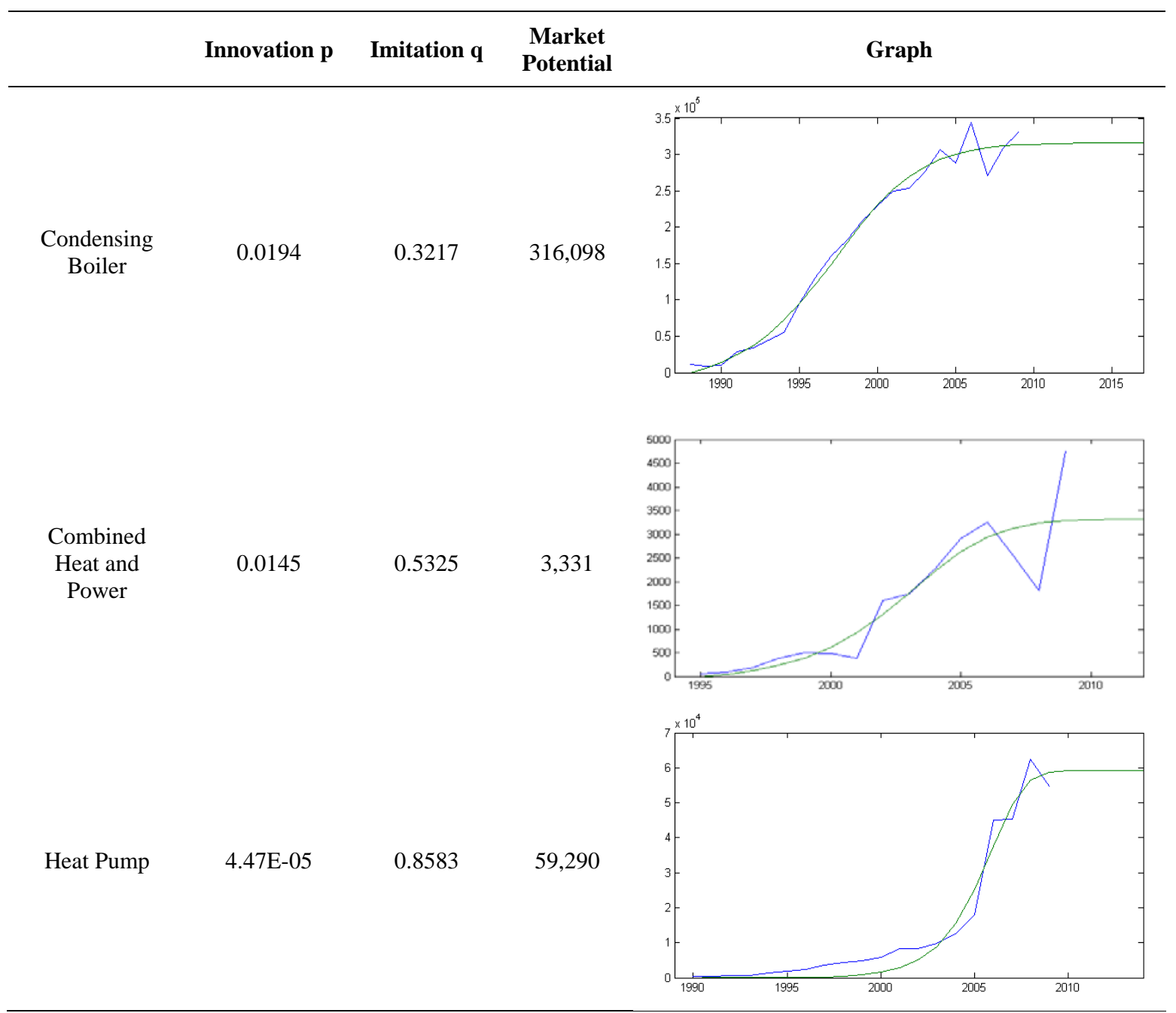

\subsection{The comparison technologies}

\subsubsection{Condensing boiler}

Over the last 20 years the gas fired condensing boiler has been the dominating technology in Germany's heating market by far. Only considering a period of 10 years from 1998 to 2009, the market share of gas fired condensing boilers rose from 10 to $50 \%$. The parameter of innovation for the past development was found, according to Bass as $p_{C B}=0.194$, imitators were represented at $q_{C B}=0.3217$ and the market potential converged at $m_{C B}=316,098$ in an overall market size of around 630,000 per annum in 2009. The simulation of gas fired condensing boilers shows the best fit between past sales numbers and the Bass model equation, displayed by a coefficient of determination of $R^{2} C B=0.9843$. These diffusion characteristics are explained by the fact that condensing boilers were relatively competitive to conventional heating systems and hence uninfluenced by fluctuating political and economic incentives. Therefore, this diffusion process can be considered an adequate model of a general diffusion process within Germany's heating appliances market. 


\subsubsection{Combined heat-and-power}

First commercially marketed combined-heat-and-power generators were introduced in the midnineties. Since then sales numbers have been constantly rising at a comparably low level and the diffusion parameters were found to be $p_{C H P}=0.0145$ and $q_{C H P}=0.5352$. Sales numbers show very high fluctuations which mainly seem to be connected to introduction, cancellation and changing of politically introduced market incentives. Following the fit between real sales numbers and the Bass model is not as precise like it is displayed by a lower coefficient of determination $R^{2}{ }_{C H P}=0.8169$. Still gas fired combined heat-and-power generators are going to be used to frame the forecast of future fuel cell development. This is mainly due to high similarities of technical nature and accordingly, very similar market shares.

\subsubsection{Heat pump}

The market diffusion process of heat pumps in the past has been extremely dependent on oil price developments. Until the late nineties the diffusion took place very slowly with a sudden explosion of sales numbers at the turn of the century. An indication for this dependency is the first commercial introduction of heat pumps in the late seventies, during the second oil crisis. Sales numbers rose drastically just to drop back to zero when oil prices stabilized again. Since the same dependency cannot be assumed for fuel cells and since price development of oil is hardly predictable, heat pump market diffusion was not used for the approximation. Still the fit of the Bass model equation is very good considering a coefficient of determination of $R^{2} H P=0.9660$.

\subsubsection{Approximation results}

The diffusion forecast is based on the past developments of Condensing Boiler and Combined heat-and-power technologies. The innovation and imitation parameters shall serve as limitations of an area of possible future developments as visualized in Fig. 5. The following calculations conducted for network scenarios and for the sensitivity analysis are derived from the averaged values for $p$ and $q$. More precisely, the values $p$ and $q$ for future fuel cell development are derived from the arithmetic mean between the diffusion parameters of the two chosen comparison technologies.

Since condensing boiler and combined heat-and-power diffusion parameters deliver both suitable features for a comparison their diffusion parameters are averaged to gain a clear arrangement in the following chapters. The resulting values for future fuel cell market diffusion are found as $p_{F C}=0.01695$ and $q_{F C}=0.42845$.

\subsubsection{Market potential}

The potential market size is obtained from Bokaemper (2002) and therefore set to $m_{F C}=25.000$. Bokaemper conducted an examination to find out if there could be a self-supporting market for fuel cell co-generators in households "as mini power plants" in Germany and what extent that market could have. With his model for the market potential, results are generated in the absence of a hydrogen network. Although that yields lower installation quantities with respect to time than in the case of applying a network to the hydrogen economy, this quantity is used as an upper installation limit for residential fuel cell systems. The aim of this paper is not to assess

Please cite this article as: Heinz, B., Graeber, M., Praktiknjo, A. (2013): The diffusion process of stationary fuel cells in a two-sided market economy. In: Energy Policy, 61: 1556-1567.

http://dx.doi.org/10.1016/j.enpol.2013.06.095 
the real market potential but to demonstrate that the diffusion process of fuel cells can be facilitated and accelerated by using the network effects. Therefore, it is justifiable to use Bokaemper's data.

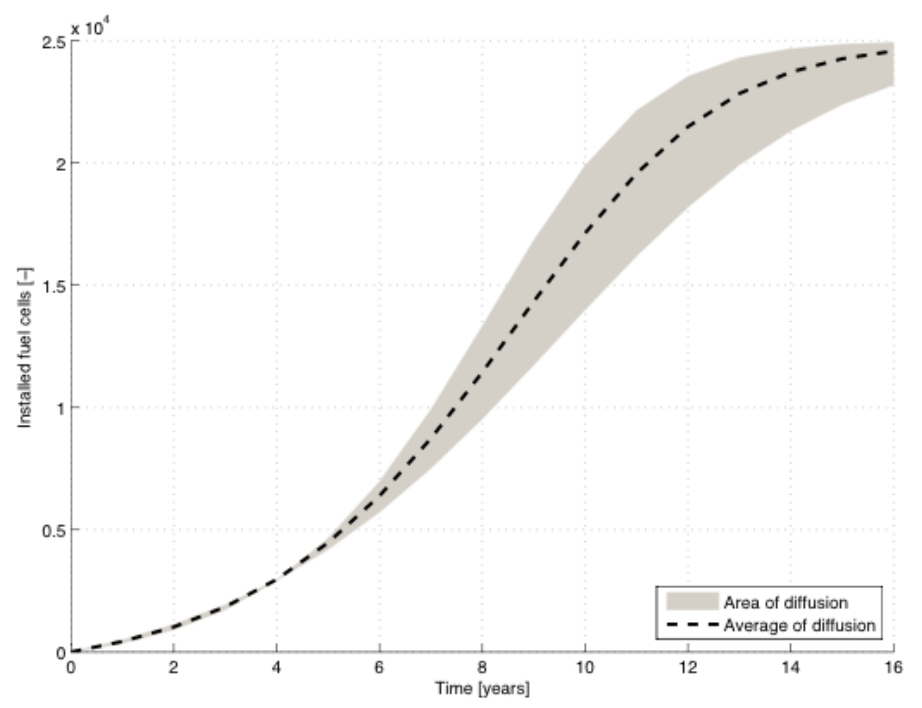

Figure 5: Standard diffusion process

Fig. 5 shows the standard diffusion scenario. The black dashed line stands for the approximated parameters for the future fuel cell market development while the grey area shows the spread between diffusion characteristics of condensing boilers and combined heat-and-power generators. This difference can be considered the likely spread of fuel cell diffusion.

\subsection{Network scenarios}

In the second, third and fourth scenarios that are shown in Fig. 6 the same- and cross-side effects have been incorporated by influencing the $p$ and $q$ values.

As mentioned in Section 4 the coefficient of imitation $q$ can be seen as representative of the same-side effect. It is obvious that its variation by including the same-side effects of the hydrogen network is carried out in positive direction as the same-side effects improve the imitation process throughout the society. With an increase of the parameter of imitation one gets an idea how the diffusion curve shifts in such a case towards higher numbers of installations per unit time. According to the expert opinion supported by a meta-study, carried out as a part of the EU-project HyFleet:CUTE (2009) ${ }^{5}$, a raise of $q$ of $30 \%$ seems to be justified. The blue curve in Fig. 6 stands for diffusion with same-side effects.

Like in Fig. 5, the ordinate in Fig. 6 shows the number of installed fuel cells and the abscissa relates it to the time. The blue curve deviates from the black one more and more with running time. That is the increasing pressure operating on the imitators in the social system to buy fuel cells. The higher the number of adopters, the higher the pressure on the imitators gets that have not yet adopted. For the other market side (fuel cell manufacturers and hydrogen producers) the same applies. Due to the pressure acting on future adopters generated by the number of previous adopters, same-side effects can be said to have some time delay in their force. 


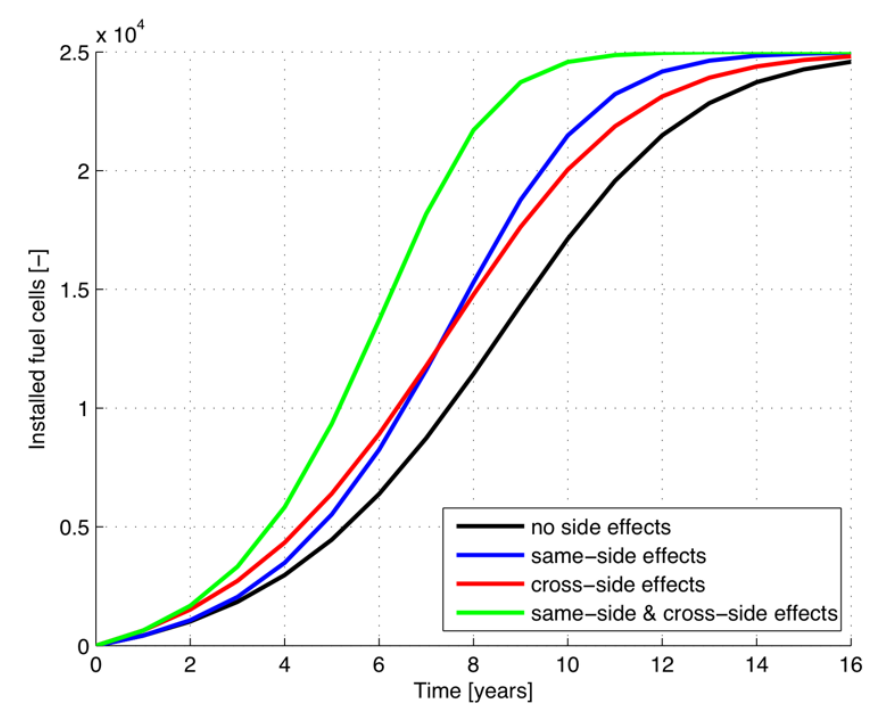

Figure 6: Diffusion process of the three scenarios

The cross-side effects in the diffusion process can be quantified with a variation of the coefficient of innovation. It stands here for a more efficient way of exchanging information from one side of the market to the other side, additionally boosted by the intermediary in between. Therefore, coefficient $p$ is set $50 \%$ higher than the average value and decreases linearly with time towards the average value of $p$. At the end of the diffusion process, the average of $p$ is again shown. The justification for this increase arises from the fact that it stands for the external influence of a social system and for the advertising effect on which significant influence can be exerted. The magnitude for $p$ was also estimated through a meta-study and a study of the effects of advertisement and additional induced sales. Furthermore, this approach corresponds to an assessment conducted by experts for that particular case. But as described above, the cross-side effects will be more dominant in the first half of the diffusion process as they encourage adopters who would have adopted later. Through the advanced information flow, they get the earlier information on which they base their decision to adopt or not. Future adoption processes will be brought forward. That is why they decrease in this case linearly with time. The corresponding cross-side curve can be seen in Fig. 6.

In the final scenario with the inclusion of same-side and cross side effects, a further relation between the two effects reinforces the diffusion process. Regarding the transfer of future adopters who adopt earlier in the diffusion process due to the cross-side effects, same-side effects also emerge earlier and with an extended impact. This can be envisaged by looking at the first adopters and innovators who get their essential information earlier and easier through the intermediary and adopt earlier. Therewith not only their adoption process is brought forward but also the imitation process of later adopters, imitators and the majority as they "learn from" and imitate the previous adopters. To cover this effect, the coefficient of imitation is set to a value of $58 \%$ above the average. The final scenario is represented by the green curve in Fig. 6. Following the curve for the final scenario over time and comparing it to the standard scenario one can quantify the spread of the number of installed fuel cells. The spread enlarges very fast in the first five to six years and then reduces slowly because the market potential for both scenarios is kept the same. It can be seen that with the utilization of the network effects fuel cell installations can be doubled within the first five years. 


\subsection{Scenario analysis}

\subsubsection{Sensitivity analysis}

To have a closer look at the relative shifts of the diffusion curve and to get an impression how robust the results are, a sensitivity analysis has been conducted for the standard scenario. As known changes in the diffusion rates occur due to variations of the two coefficients in the Bass diffusion model. Hence in Fig. 7 and in Fig. 8 the standard scenario diffusion curve with average values for the coefficients is plotted in black.

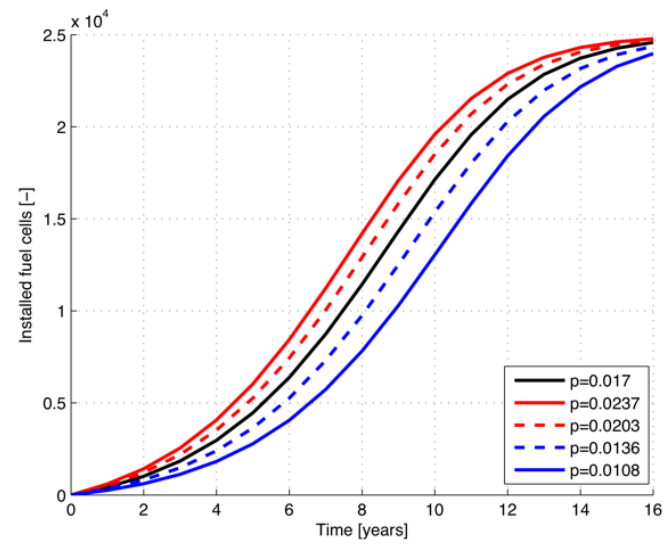

Figure 7: Standard diffusion curve by variation of coefficient of innovation (p)

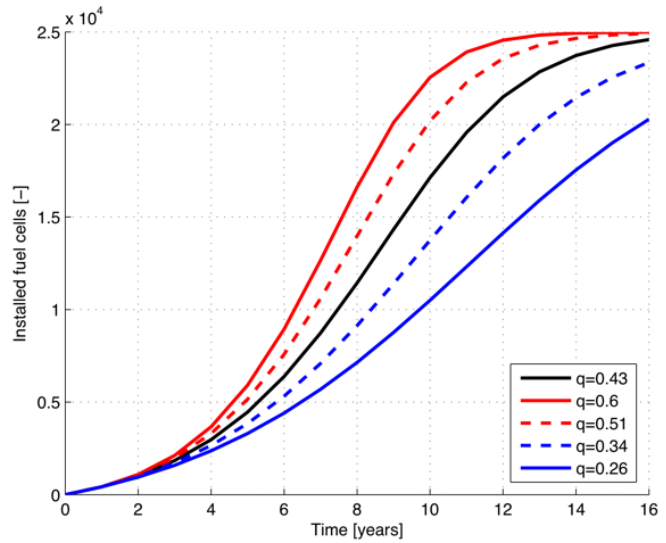

Figure 8: Standard diffusion curve by variation of coefficient of imitation (q)

Additionally, there are red curves with higher coefficients and blue curves with lower coefficients. Stepwise the average value is increased and decreased by $20 \%$, respectively. The coefficient of innovation that is varied in Fig. 7 shows its shifting effect over the whole time constantly with an exception at the start and at the end of the diffusion process because the numbers for installed fuel cells is fixed. In contrast, the variation of the coefficient of imitation bears more at the end of the diffusion time period. Imitators who adopt are very few at the beginning but will appear more and more with increasing previous adopters which means with increasing time.

\subsubsection{Intra-annual variation of the outcomes}

Using the Bass diffusion model to forecast dissemination of fuel cells we act in a new and unknown area. Therefore, there is some uncertainty about the computed data. For the standard diffusion scenario, we used a method of regression to achieve comparable diffusion values. This led to a likely scenario for fuel cell diffusion. The three network scenarios were computed on the basis of means which have been adjusted. But point estimates like the means used do not consider variation or distribution around the estimates. Thus, we also have to account for dispersion, skew and kurtosis of the outcomes. In Fig. 9 we plot the installed fuel cells against the diffusion parameters $p$ and $q$ which results in areas for each year. Each area visualizes all possible numbers of installed fuel cells for each year which can be calculated subject to the coefficients $p$ and $q$. The value limits chosen for $p$ and $q$ in the area diagram account for the typical spectrum of Bass's diffusion model parameters (Bass, 1967). As the model is designed, the graphic shows that the highest values of installed fuel cells are reached with the highest values of $p$ and $q$. It can be determined that the functional relation of the parameter $p, q$ and the 
function of the number of installed fuel cells shows a strictly monotonic increase. That means that variations in the near surrounding of the values used for our diffusion scenario can be approximated by a linear relationship. Checking the slope of the area diagram with respect to $p$ and $q$ one can see that it is very high at the right of the graph (for lower $p$ and $q$ ) and flattens out to a very low slope on the left towards higher $p$ and $q$. Checking the slope of the area diagram around the $p$ and $q$ values used in our final diffusion scenario $(p=0.025, q=0.68)$ one finds a very low slope for the innovation parameter. Including this into the sensitivity analysis, one can say, that changes in the parameter $p$ have very low impact on the resulting number of installed fuel cells for this year. For the imitators influence though, the situation is entirely different, since the slope in the surrounding area is quite high. Changes in the parameter $q$ have a relatively high impact on sales numbers.

The final scenario chosen for future fuel cell development is represented by the black line, crossing the area diagram vertically.

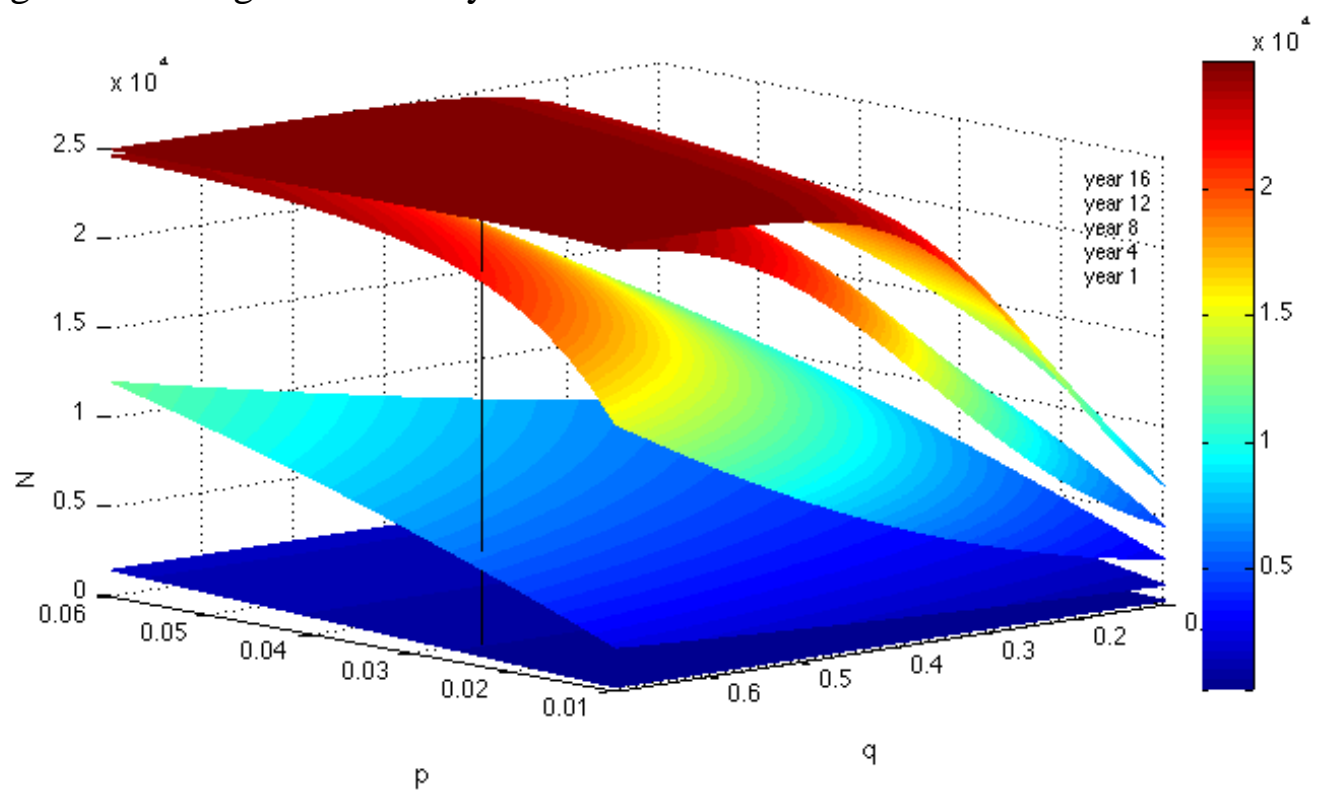

Figure 9: Installed fuel cells at the end of years 1, 4, 8, 12, and 16 subject to the parameters $p$ and $q$

The dark blue surface is the result for the first year. With our adjusted coefficient of $p$ and $q$ the diffusion model delivers 635 installed fuel cells. The minimum and maximum values for each year and the values calculated in our final scenario are listed in Table 2. The expected number of installed fuel cells in the fourth year, 5877, is significant higher but still has growth potential compared to the maximal value. Only four years later we obtain almost the maximum number of the possible installed fuel cells-21,710. In just half the anticipated diffusion time of 16 years we almost reach the entire market potential. 
Table 2: Minimum expected and maximum number of installed fuel cells

\begin{tabular}{lccc}
\hline & $\begin{array}{c}\text { Minimum number } \\
\text { of fuel cells }\end{array}$ & $\begin{array}{c}\text { Final scenario } \\
\text { of model }\end{array}$ & $\begin{array}{c}\text { Maximum number } \\
\text { of fuel cells }\end{array}$ \\
\hline Year 1 & 424 & 635 & 1500 \\
Year 4 & 2968 & 5877 & 12,183 \\
Year 8 & 11,443 & 21,710 & 24,678 \\
Year 12 & 21,488 & 24,961 & 24,999 \\
Year 16 & 24,582 & 25,000 & 25,000 \\
\hline
\end{tabular}

\section{Conclusions, limitations and further research}

First, we demonstrate that the hydrogen economy can be described as a network economy. Ongoing, we introduce the novel approach of two-sided markets and apply it to the hydrogen market. As a key finding, we show that utilizing the two-sided market effects can accelerate the diffusion process of fuel cells. Finally, an intermediary is able to help to overcome the prevalent problem of establishing a network.

Thus, the hydrogen economy features the special characteristics of network effects and the chicken-and-egg problem. That followed, we present the innovative marketing concept of twosided markets and apply it to that hydrogen economy. In general, network effects are considered as a problem, but we show that utilizing the positive interdependencies between supply and demand is possible and is even able to implement a physical network consisting of fuel cell manufacturers, hydrogen suppliers and consumers of both goods. Starting from that point, we also demonstrate that the two-sided market approach can be applied in the hydrogen market and that its interrelations can be captured and visualized by the Bass diffusion model. Using the network effects can not only overcome the market failure due to the externalities but also accelerate the market diffusion of fuel cells and the hydrogen producers.

The modelled network scenarios in this paper highlight that the diffusion process of fuel cells can be accelerated significantly. The standard scenario indicates a slow diffusion of fuel cells because the two-sided market effects are not used. The implication is that in a highly fragmented fuel cell market the entrance of hydrogen producers is very unlikely or at least takes long. Therefore, the probability for high volumes of sales of fuel cells is also low. In the second scenario, the distribution is faster because of the economic utilization of cross-side and sameside effects. Combining cross-side and same-side effects leads to the fastest diffusion process. As a result, it is demonstrated that the diffusion rate can speed up so much that the installation base of fuel cells can be doubled in the first 5 years.

To accelerate the diffusion, process the network effects should be moderated by a broker. Then an implementation of locally distributed fuel cells for decentralized energy supply based on hydrogen can be a realistic alternative to current technologies. If policy-makers, fuel cell and hydrogen producers established a platform-intermediary, same-side and cross-side network effects could be used most powerful.

Henkel (2012) showed that subsidies accelerate the diffusion of innovative heating technologies. In case of fuel cells, subsidies could lead to a higher adoption rate.

The paper provides a first estimation of the use of two-sided market effects in a fuel cell diffusion process but there are limitations. It shall be highlighted, that the results for our standard diffusion process can only be seen as a first approach to predict a possible market development.

Please cite this article as: Heinz, B., Graeber, M., Praktiknjo, A. (2013): The diffusion process of stationary fuel cells in a two-sided market economy. In: Energy Policy, 61: 1556-1567.

http://dx.doi.org/10.1016/j.enpol.2013.06.095 
Furthermore, investment costs were not considered, even though their influence on adoption rates will be huge. There are various uncertainties in the model since it cannot be sure at this point how the market will react to fuel cell introduction as a heating appliance. The different network scenarios are an approach to illustrate this. Imponderability is mainly introduced to the model's findings by outer effects on the market participants. Three main examples shall be given as follows:

\subsection{Political influence}

Further pressure will be introduced on fossil fuel consuming technologies, such as condensing boilers. This will be institutionalized by legal changes mainly within EnEV regulations. This will raise pressure on the different market participants and technologies such as hydrogen fired fuel cells will most likely benefit despite higher investment costs.

\subsection{Technological influence}

The technical progress within hydrogen applications is not limited to developments within heating technology. The achievements related to hydrogen fueled electric mobility are an integral part of which direction fuel cell development will take. If fuel cells are able to establish themselves as a main source of energy within traffic applications in the future, fuel cells used as heating appliances might also benefit from this. This will include economic as well as technological benefits that will have a major impact on consumers' behavior and therewith on fuel cell market diffusion.

\subsection{Rising prices for fossil fuels}

The past has shown that prices of fossil fuels cannot be considered stable and predictable. In times of fossil fuel prices rising rapidly, technologies independent of those fuels always showed immense increase in sales numbers despite possible burdens introduced by higher investment costs. At the same time, stabilizing oil prices lead to a quick re-adoption of conventional technologies.

Considering the arguments listed above, it shall be highlighted that the development predicted in this approach can rather be seen as a guideline. Rising knowledge of the market development and the outer forces taking effect within the consumers and producers network will have to be incorporated in the presented model to raise its precision and accountability.

As we use only two parameters and account the higher $p$ parameter to the effects only caused by the coordination of the information by the intermediary, we disregard the same-side effects of the business-to-business market side (market side 1). As a result, we probably underestimate the diffusion speed in our model. Therefore, a further adjustment of the Bass diffusion model for two-sided markets should be provided in further research. 


\section{References}

Akerlof, G.A., 1970. The Market for "Lemons": Quality Uncertainty and the Market Mechanism, The Quarterly Journal of Economics, 84(3), 488-500.

Armstrong, M., 2006. Competition in two-sided markets, RAND Journal of Economics, 37(3), 668-691.

Bakos, Y., 1997. Reducing Buyer Search Costs: Implications for Electronic Marketplaces, Management Science, 43(12), 1676-1692.

Barreto, L., Makihira, A., \& Riahi, K., 2003. The hydrogen economy in the 21st century: a sustainable development scenario, International Journal of Hydrogen Energy, 28(3), 267-284.

Bass, F.M., 1967. A new product growth model for consumer durables, Purdue Working Paper, 1967.

Bass, F.M., 1969. A new product growth for model consumer durables, Management Science, 15, 215-227.

Birkner C., Heinz B., June 18-20 2008. Accelerating the hydrogen economy by using two-sided market effects, 31st IAEE International Conference, Istanbul, Turkey.

Bokaemper, S., 2002. Marktperspektiven von BZ-Heizgeraeten - Eine ökonomische Systemanalyse, Ph.D. Thesis, Department of Energy Systems, Technische Universität Berlin, www.dissertation.de.

Caillaud, B., Jullien, B., 2003. Chicken \& egg: Competing match-makers, RAND Journal of Economics, 34(2), 309-328.

Decanio, S.J., Laitner, J.A., 1997. Modeling Technological Change in Energy Demand Forecasting, Technological Forecasting and Social Change, 55, 249-263.

Eisenmann, T., Parker, G., Van Alstyne, M.W., 2006. Strategies for two-sided markets, Harvard Business Review, 10, 92-101.

Gupta, S., Cain, D.C., Sawhney, M.S., 1999. Modeling the Evaluation of Markets with Indirect Network Externalities: An Application to Digital Television, Marketing Science, 18(3), 396-416.

Henkel, J., 2012. Modelling the Diffusion of Innovative Heating Systems in Germany - Decision Criteria, Influence of Policy Instruments and Vintage Path Dependencies, Ph.D. Thesis, Department of Energy Systems, Technische Universität Berlin, Universitätsbibliothek.

Kalish, S., Lilien, G.L., 1983. Optimal Price Subsidy Policy for Accelerating the Diffusion of Innovation, Marketing Science, 2(4), 407-420.

Katz, M.L., Shapiro, C., 1985. Network externalities, competition, and compatibility, American Economic Review, 75(3), 424-440.

Katz, M.L., Shapiro, C., 1994. Systems Competition and Network Effects, Journal of Economic Perspectives, 8(2), 93-115.

Lawrence, K.D., Lawton, W.H., 1981. Applications of Diffusion Models: Some Empirical Results, New Product Forecasting, Lexington, Lexington Books, 529-541.

Meade, N., Islam, T., 2006. Modelling and forecasting the diffusion of innovation - A 25-year review, International Journal of Forecasting, 22, 519-545.

Parker, G., Van Alstyne, M.W., 2005. Two-Sided Network Effects: A Theory of Information Product Design, Management Science, 51(10), 1494-1504.

Rochet, J.-C., Tirole, J., 2003. Platform Competition in Two-Sided Markets, Journal of the European Economic Association, 1(4), 990-1029.

Rogers, E.M., 2003. Diffusion of innovations, 5th Edition, New York, Free Press.

Stremersch, S., Tellis, G.J., Franses P.H., Binken J.L.G., 2007. Indirect Network Effects in New Product Growth, Journal of Marketing, 71, 52-74.

Sultan, F., Farley, J.U., Lehmann, D.R., 1990. A Meta Analysis of Diffusion Models, Journal of Marketing Research, 27, 70-77.

Sun, M., Tse, E., 2007. Sustainable Growth of Payment Card Networks: A Two-Sided Market Approach, Journal of Business Strategies, 1(2), 165-191.

Please cite this article as: Heinz, B., Graeber, M., Praktiknjo, A. (2013): The diffusion process of stationary fuel cells in a two-sided market economy. In: Energy Policy, 61: 1556-1567.

http://dx.doi.org/10.1016/j.enpol.2013.06.095 


\section{Footnotes}

${ }^{1}$ In this paper network externalities and network effects are used synonymously

${ }^{2}$ Within the European HyWays project the main sources for hydrogen production in the future have been assessed by European stakeholders. Accordingly, hydrogen production from wind energy will have the biggest share with $30 \%$. The HyWays project is part of the European Commission's $6^{\text {th }}$ framework programme.

${ }^{3}$ In literature cross-side network effects are also named cross-group network effects and inter-market network externalities.

${ }^{4}$ In literature same-side network effects are also named within-group network effects and intra-market network externalities.

${ }^{5}$ More information about the HyFleet:Cute project can be found on http://www.global-hydrogen-busplatform.com/

Please cite this article as: Heinz, B., Graeber, M., Praktiknjo, A. (2013): The diffusion process of stationary fuel cells in a two-sided market economy. In: Energy Policy, 61: 1556-1567.

http://dx.doi.org/10.1016/j.enpol.2013.06.095 


\section{Appendix}

\section{Assumptions and the Model according to Bass (1969)}

The following assumptions characterize the model:

a) Over the period of interest (life of the product) there will be m initial purchases of the product. Since we are dealing with infrequently purchased products, the unit sales of the product will coincide with the number of initial purchases during that part of the time interval for which replacement sales are excluded. After replacement purchasing begins, sales will be composed of both initial purchases and replacement purchases. We shall restrict our interest in sales to that time interval for which replacement sales are excluded, although our interest in initial purchase will extend beyond this interval.

b) The likelihood of purchase at time $T$ given that no purchase has yet been made is

$$
\frac{[f(T)]}{[1-F(T)]}=P(T)=p+\frac{q}{m} \times Y(T)=p+q \times F(T),
$$

where $f(T)$ is the likelihood of purchase at $T$ and

$$
F(T)=\int_{0}^{T} f(t) \times d t, F(T)=0
$$

Since $f(T)$ is the likelihood of purchase at $T$ and $m$ is the total number purchasing during the period for which the density function was constructed,

$$
Y(T)=\int_{0}^{T} S(t) \times d t=m \int_{0}^{T} f(t) \times d t=m \times F(T)
$$

is the total number purchasing in the $(0, T)$ interval. Therefore, sales at $T$ equal

$$
S(t)=m \times f(t)=P(T) \times[m-(T)]=\left[p+\frac{q}{m} \times \int_{0}^{T} S(t) \times d t\right] \times\left[m-\int_{0}^{T} S(t) \times d t\right] .
$$

Expanding this product we have

$$
S(T)=p \times m+(q-p) \times Y(T)-\frac{q}{m} \times[Y(T)]^{2} .
$$

The behavioral rationales for these assumptions are summarized:

a) Initial purchases of the product are made by both "innovators" and "imitators", the important distinction between an innovator and an imitator being the buying influence. Innovators are not influenced in the timing of their initial purchase by the number of people who have already bought the product, while imitators are influenced by the number of previous buyers. Imitators "learn" in some sense, from those who have already bought.

b) The importance of innovators will be greater at first but will diminish monotonically with time. 
c) We shall refer to $p$ as the coefficient of innovation and $q$ as the coefficient of imitation. Since $f(T)=[p+q \times F(T)] \times[1-F(T)]=p+(q-p) \times F(T)-q \times[F(T)]^{2}$, in order to find $F(T)$ we must solve this non-linear differential equation:

$$
d T=\frac{d F}{p+(q-p) \times F-q \times F^{2}} .
$$

The solution is:

$$
F=\frac{q-p \times e^{-(T+C) \times(p+q)}}{q \times\left(1+e^{-(T+C) \times(p+q)}\right)} .
$$

Since $F(0)=0$, the integration constant may be evaluated:

$$
-C=\frac{1}{(p+q)} \times \ln \left(\frac{q}{p}\right) \text { and } F(T)=\frac{1-e^{-(p+q) \times T}}{p \times e^{-(p+q) \times T}+1}
$$

Then

$$
\begin{gathered}
f(T)=\frac{(p+q)^{2}}{p} \times \frac{e^{-(p+q) \times T}}{\left(\frac{q}{p \times e^{-(p+q) \times T}}+1\right)^{2}}, \\
\text { and } \\
S(T)=\frac{m \times(p+q)^{2}}{p} \times\left[\frac{e^{-(p+q) \times T}}{\left(\frac{q}{p \times e^{-(p+q) \times T}}+1\right)^{2}}\right] .
\end{gathered}
$$

To find the time at which the sales rate reaches its peak, we differentiate $S$,

$$
S^{\prime}=\frac{\left(\frac{m}{p}\right) \times(p+q)^{3} \times e^{-(p+q) \times T} \times\left(\frac{q}{p} \times e^{-(p+q) \times T}-1\right)}{\left(\frac{q}{p} \times e^{-(p+q) \times T}+1\right)^{3}} .
$$

Thus, $\quad T=-\frac{1}{p+q} \times \ln \left(\frac{p}{q}\right)=\frac{1}{p+q} \times \ln \left(\frac{q}{p}\right)$ and if an interior maximum exists, $q>p$.

We note that $S(T)=\frac{m \times(p+q)^{2}}{4 \times q}$ and $Y(T)=\int_{0}^{T} S(t) \times d t=\frac{m \times(q-p)}{2 \times q}$. Since for successful new products the coefficient of imitation will ordinarily be much larger than the coefficient of innovation, sales will attain its maximum value at about the time that cumulative sales are approximately one-half $\mathrm{m}$. We note also that the expected time to purchase, $E(T)$, is $\frac{1}{q} \times \ln \left(\frac{p+q}{p}\right)$.

The discrete analogue can be found to be $S(T)=p \times m+(q-p) \times Y(T)-\frac{q}{m} \times Y(T)^{2}$. 